\title{
EGU21-8079
}

https://doi.org/10.5194/egusphere-egu21-8079

EGU General Assembly 2021

(c) Author(s) 2021. This work is distributed under

the Creative Commons Attribution 4.0 License.

\section{Improved three-dimensional image of the tomographic inversion of the Arraiolos aftershock sequence.}

\author{
Ines Hamak ${ }^{1}$, Piedade Wachilala ${ }^{1,2}$, José Borges ${ }^{1}$, Nuno Dias ${ }^{3,4}$, Inês Rio ${ }^{4}$, and Mourad Bezzeghoud ${ }^{1}$ \\ ${ }^{1}$ Universidade de Evora, Instituto de Investigação e Formação Avançada, Geophysics, Evora, Portugal \\ (hamak.ines@gmail.com, piedadewachilala@gmail.com, jborges@uevora.pt,mourad@uevora.pt,) \\ ${ }^{2}$ Instituto Superior de Ciências de Educação da Huíla, Departamento de Ciências da Natureza, Angola \\ (piedadewachilala@gmail.com) \\ ${ }^{3}$ Instituto Superior de Engenharia de Lisboa, Department of Physics, Lisbon, Portugal (nmdias@fc.ul.pt) \\ ${ }^{4}$ Instituto Dom Luiz (IDL), University of Lisbon, Lisbon, Portugal (irio@fc.ul.pt, nmdias@fc.ul.pt)
}

This work puts in light the several steps followed to obtain a 3D velocity model in Arraiolos, a region located in central Portugal. After the earthquake of January 2018 occurred, a set of stations were deployed around the main shock area and has recorded the aftershock sequence during a period of six months.

The first stage of this study used a set of data recorded along the $1^{\text {st }}$ month by 21 temporary seismological stations. 317 aftershocks were used to invert a 3D P and S velocity model, using LOTOS program, and showing an agglomeration of events in one local point leading to a poor resolution. Therefore, we added more stations and data to the second stage of study by integrating 437 aftershocks recorded during a period of 6 months by a set of 34 stations. The tomographic inversion of this extended aftershock sequence has shown a significant improvement of the 3D velocity model resolution and suggesting an alignment of the seismic events cluster. However, the imaged crustal volume was still too small and possessing low resolution on the edges of the area. To fix this issue, additional data and seismological stations were integrated to the study in order to increase the area of interest and cover it entirely in terms of ray density.

The step which we are currently conducting concerns the location of new events followed by their integration to the tomographic study using IPMA and DOCTAR station network records. Since the later phases PmP and SmS has the potential to increase the ray coverage as similarly as the resolution of an area, we will hopefully obtain, after their integration, significant improvements in terms of accuracy and reliability of the crustal image. The main purpose of this new stage of study is to finally provide significant interpretations and figure out precisely the tectonic processes having generated the Arraiolos seismicity.

Thanks are due to FCT for the financial support to the ICT project (UID/GEO/04683/2013) with the reference POCI-01- 0145-FEDER-007690, to the IDL project (UIDB/50019/2020 - IDL). 